\title{
Correction to: Inversion and extension of the finite Hilbert transform on $(-1,1)$
}

\author{
Guillermo P. Curbera ${ }^{1}$ (D) Susumu Okada ${ }^{2} \cdot$ Werner J. Ricker $^{3}$
}

Published online: 2 July 2019

(c) Fondazione Annali di Matematica Pura ed Applicata and Springer-Verlag GmbH Germany, part of Springer Nature 2019

\section{Correction to: Annali di Matematica Pura ed Applicata (1923-) https://doi.org/10.1007/s10231-019-00837-w}

Unfortunately, the original article contained few typesetting errors in the equations. The corrected equations are given below.

(1) Line 250 the equation should be:

$$
T\left(g T_{X}\left(f_{n}\right)+f_{n} T_{X^{\prime}}(g)\right)=\left(T_{X}\left(f_{n}\right)\right)\left(T_{X^{\prime}}(g)\right)-f_{n} g, \quad \text { a.e. },
$$

(2) Line 649 the equation should be:

$$
\|h\|_{L^{1}} \leq\left(4 \pi / \varphi_{X}(1)\right)\|h\|_{[T, X]}, \quad h \in[T, X],
$$

The original article has been corrected.

Publisher's Note Springer Nature remains neutral with regard to jurisdictional claims in published maps and institutional affiliations.

The original article can be found online at https://doi.org/10.1007/s10231-019-00837-w.

\footnotetext{
$凶 \quad$ Guillermo P. Curbera

curbera@us.es

Susumu Okada

susbobby@grapevine.com.au

Werner J. Ricker

werner.ricker@ku.de

1 Facultad de Matemáticas and IMUS, Universidad de Sevilla, Calle Tarfia s/n, 41012 Sevilla, Spain

2 School of Mathematics and Physics, University of Tasmania, Private Bag 37, Hobart, TAS 7001, Australia

3 Math.-Geogr. Fakultät, Katholische Universität Eichstätt-Ingolstadt, 85072 Eichstätt, Germany
} 